\title{
Investigating bending strength of spur gear: A review
}

\author{
Ismail Ali Abdul Aziz ${ }^{1, *}$, Daing Mohamad Nafiz Daing Idris ${ }^{1}$, and Wafiuddin Mohd \\ Ghazali $^{1}$ \\ ${ }^{1}$ Faculty of Mechanical Engineering, Universiti Malaysia Pahang, 26600 Pekan, Pahang, Malaysia,
}

\begin{abstract}
Gear tends to play a very vital role in all industries. As other mechanical systems, it is subject to design parameter, installation errors, method of manufacture and load uncertainties arising from randomness. Before engineers could design an efficient and safe gear, it is importance to understand how gear can fail is much needed. This article reviews the methodology used to investigate bending strength of spur gear; Finite Element Method (FEM), Numerical Calculation and Investigational Techniques were usually carried out in order to understand the bending strength of thin-rimmed spur gear. Works and experiment from the literature were studied, and their findings were extracted to understand the methods used. The most common method used to investigate bending strength is the numerical calculation. This method was used with several types of established equations and standards to predict gear failures. Next stage is to simulate the gear using Finite Element Method (FEM) in order to get the analysis of gear strength. The most important stage is to put the gears to physical experiment or testing facilities to determine and validate all data from the numerical calculation and FEM method.
\end{abstract}

\section{Introduction}

Nowadays, there are huge demands to have lightweight and efficient gear in the industry especially in aerospace and transportation applications[3]. Since the creation of gearing system to transmit water from river thousand years ago, the importance of gearing system become more crucial. With growing demands for a sustainable environment, it is an utmost importance for industries to save natural resources and cut the global carbon footprint [4]. Aircraft manufacturers and automakers are showing more interest in developing innovative solutions that reduce emissions with improved fuel economy by reducing weight. In gearing applications such as gearbox for vehicles and aircraft, thin-rimmed gears can help to reduce the weight of gearbox. Therefore, the usage of thin-rimmed gear became more important and often used in an application where lightweight and compact designs were demand.

Gears could fail in many unlike ways, and except for an increase noise level and vibration, there is no early indication of difficulty until total failure occurs[5]. The general types of failure modes (in decreasing order of frequency) include fatigue[6], fracture[7],

\footnotetext{
*Corresponding author: asmaelali82@gmail.com
} 
wear[8], and stress rupture. Gear tooth failures occur in two distinct regions, the tooth flank and the root fillet[9]. For thin-rimmed gears, bending stress can be different because of rim and web thickness factor [10-12]. In thin-rimmed case, the rim of a gear usually fails between two adjacent teeth. Cracks propagate through the rim and into the web[12]. Sometimes cracks immerge in the web near the rim and web joint without disturbing the rim itself. Damaged gear can cause the entire operation of a machine to come to a standstill. Therefore fracture of gear tooth is the cause to be most concerned about, and worst can lead to the destruction of the machine. A crack patenting in the root section of gear tooth mostly end up with gear tooth failure from bending fatigue. There was usually evidence of a fatigue focal point of the break that leads to fracture under cyclic loading. Tooth fracture also occurs under overload loading. Tooth breakage caused by an overload, which exceeds the tensile in a short-cycle break, has a finer stringy appearance but still displays evidence of being pulled apart abruptly [1].

The importance of understanding on how gear can fail is much needed before engineers could design efficient and safe gears. Fig. 1 shows approaches done via various research in understanding gear bending strength. Gear testing can help designers to understand various kinds of gear failures, as well as estimating the gear life in service[13]. The aid to the designer is the ability to recognize the exact type of initial failure and come out with a method to avoid those failures. There are several numerical standards used to design gear as published by American Gear Manufacturers Association (AGMA) and International Organization for Standardization (ISO) with complex equations and calculations. In addition, Finite Elements Method (FEM) used to predict gear failure, estimates gears life in service[14] and later being verified by experimental test on bending strength. On top of numerical calculation and FEM, experimental gear testing is the best approach to find out gear bending strength. Gear design calculations and experimental tests are necessary to develop and confirm a hypothesis for the probable cause of failure [2].

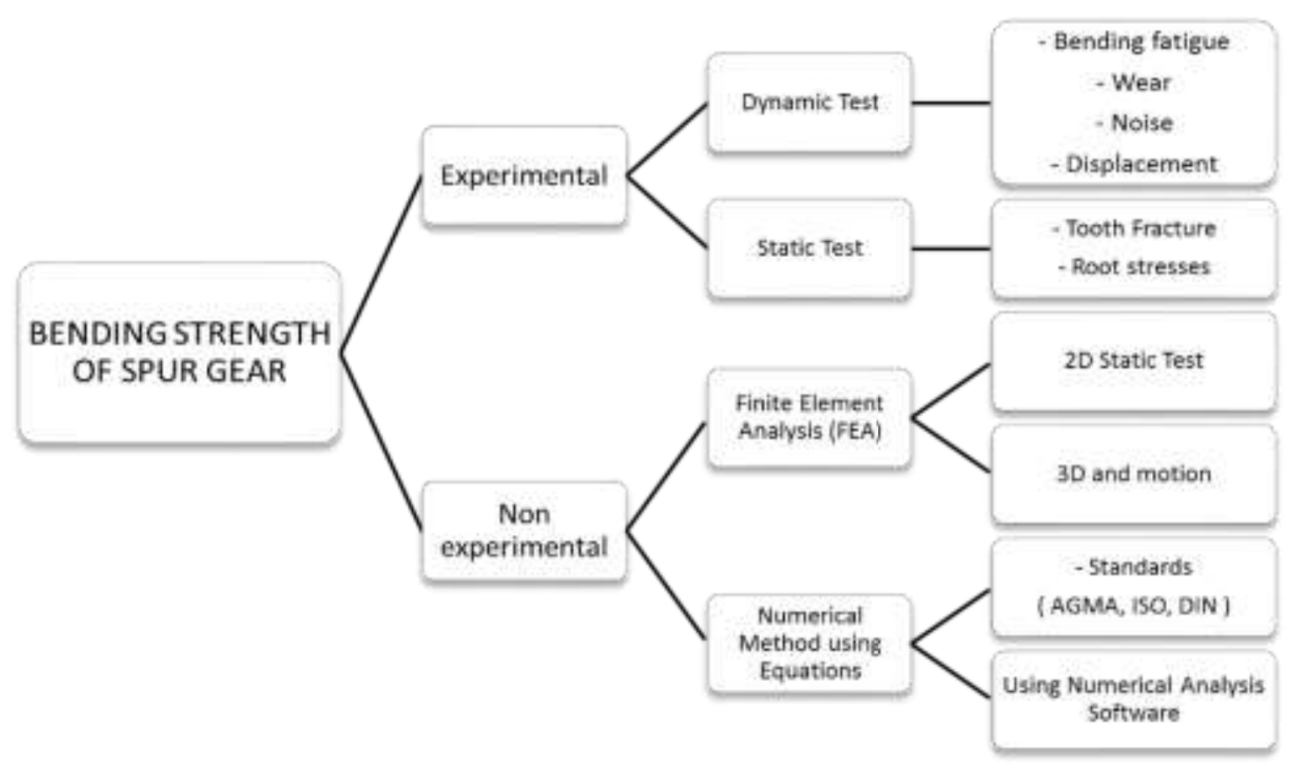

Fig. 1. Approach in understanding gear bending strength. 


\subsection{Gear failures}

A pair of gear tooth in action generally subjected to cyclic stress failure that includes toothbending fatigue, tooth-bending impact, and tooth wear[1]. Gear tooth failures occur in two distinct regions, the tooth flank, and the root fillet. Gear can fail in several modes as shown in Fig. 2.

A fracture of a tooth is the cause to be most concerned about as damaged gear can cause the entire operation of a machine to come to a standstill and worst can lead to the destruction of the machine. Tooth breakage caused by an overload, which exceeds the tensile in a short-cycle break, has a finer stringy presence but still shows evidence of being pulled apart abruptly [1]. In thin-rimmed case, sometimes cracks appear in the web near the rim and web junction without disturbing the rim itself. The rim of gear might fail between two adjacent teeth. Cracks spread through the rim and into the web. Gear tooth failure from bending fatigue generally appears from a crack initiation at the root section of the gear tooth[6]. There are other causes lead to bending fatigue failures, too much load, and cyclic loading that stress at the gear tooth beyond the endurance limits of the material may be one of major concern.

Gear tooth failure from bending fatigue mostly resulted from a crack patenting in the root section of the gear tooth. Based on gears rotational motion and the amount of load they carry, it's subjected to fatigue[15]. Failures that occur under applied load less than 10, 000 cycles considered as low cycle fatigue. Whereas high cycle fatigue defines as a failure that occurred after more than 10,000 cycles of applied load. The stress levels involved in low cycle fatigue are normally higher than the yield strength of the material.

As the nature of gearing system to have contact with each other, it tends to wear out. The most common wear failure is moderate wear. This type of wear happens for a huge number of cycles and might involve lack of lubricant or fine dirt in the system. Abrasive wear occurs due to the presence of metal particles from the gears and bearings, weld spatters, scale, rust, sand and dirt in the lubricant of the gears [1]. Meanwhile, corrosive wear happens due to corrosion action on the teeth of the gears. This type of wear failure is visually looked at as spotty dots appearing scattered on the tooth of the gear.

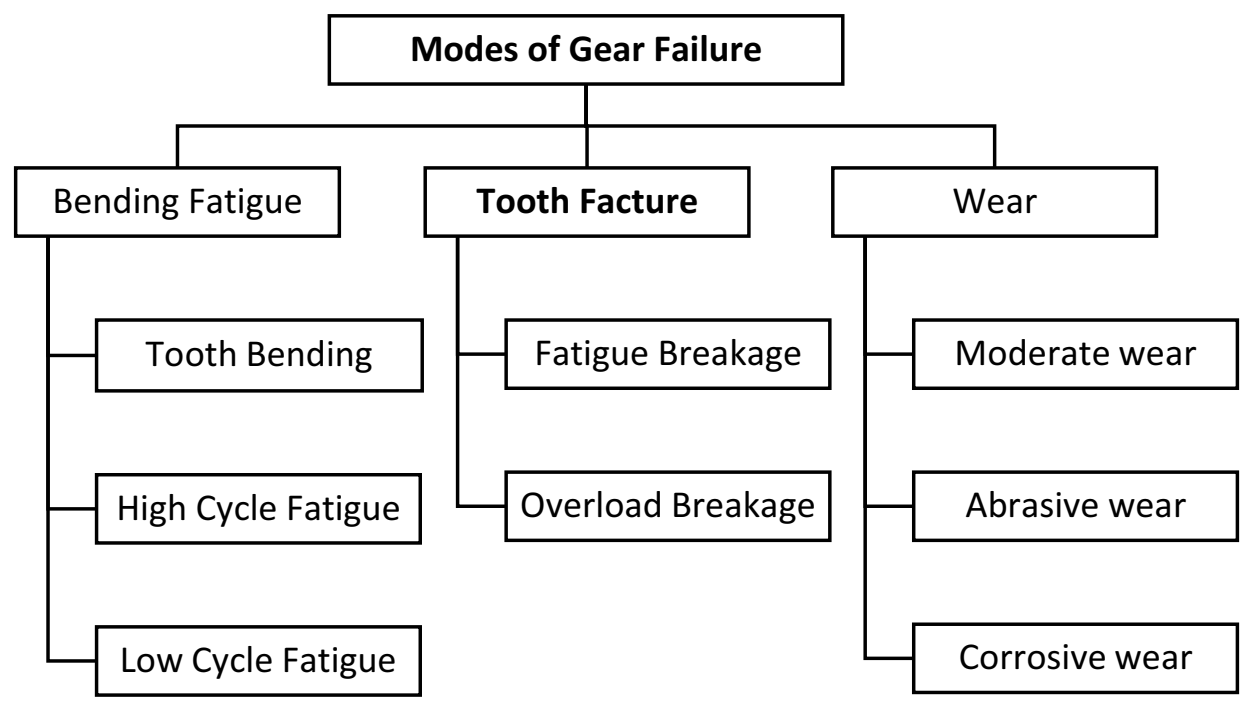

Fig. 2. Modes of Gear Failure[1, 2]. 


\section{Finite element method (FEM)}

Before actual experiment was conducted on a specimen, usually researchers will conduct simulations of the specimen. Works that use the finite element method could help the researchers to predict and understand the bending strength of gear before conducting a physical experiment or testing.

Toni Jabbour et. al[16] verified their calculation of the root and contact stresses with finite element calculations. Another gear associated to enable the simultaneous rotation of the two gears with consistent gear ratio. In order to choose the most effective mesh refinement, the maximum contact pressure values, obtained from several analyses were compared because the precision of the contact pressure value depends on the number of elements. From Finite element calculation, the critical tooth-root stress which leads from the position of the point of contact depends on the contact ratio of the pair of gears the increases number of gear teeth.

Jiaxing Zhan et. al[17] suggested that attention should be given to the tip relief of gear when conducting testing on gears. From their simulation, contact stress was decreased constantly when teeth pair starts to contact. Tooth tip with no modification indicates reading up to $476 \mathrm{MPa}$ in contact stress value compare to the tip radius of $1.00 \mathrm{~mm}$ indicates $190 \mathrm{MPa}$. This five teeth gear model were fine meshed with up to 31740 elements and the total number of nodes was 143 938.Tthe time-varying load capacity of gears could be demonstrated in the quasi-static FEM in a complete mesh cycle.

A most recent study by Vincent Savaria [4] used FE model calibrated with representative axial and torsion laboratory specimens, based on the well-known Crossland criterion. The geometry used was a simplified 3D FE model including only one tooth and being compared to Von Mises strain maps obtained by digital image correlation and the FE model as shown in Fig. 3. Results from 3D FE model shows the maximum root bending stress was up to $2083 \mathrm{MPa}$ on model A while $1651 \mathrm{MPa}$ for model D and baseline model with no induction shows $1049 \mathrm{MPa}$ of maximum root bending stress. Results from FEA test were validated from data obtained by experiment on single tooth bending fatigue rig (STBF).

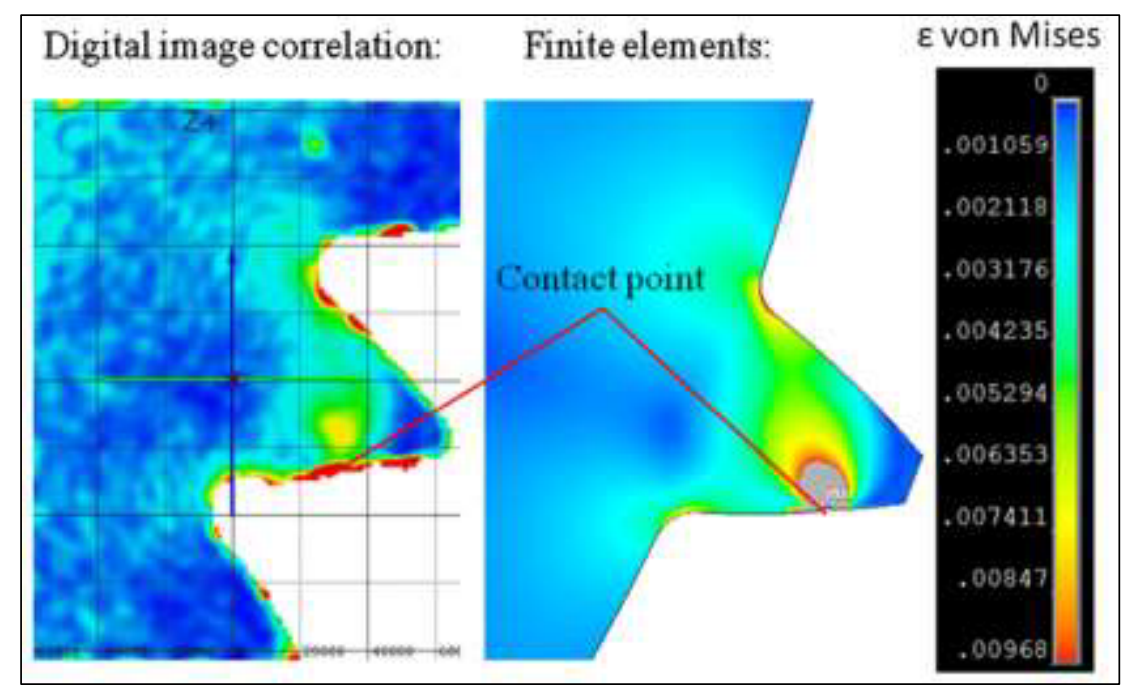

Fig. 3. Comparison of Von Mises strain maps obtained by digital image correlation and the FE model [4]. 
In order to reduce bending stress in external spur gears by redesign the standard cutting tools, Niels L. Pederson [18] simulated Finite Element Modelling of external spur gear with Poisson's ratio of $v=0.3$. The load and supports, as well as, the geometry were earlier specified. Results from FEA simulated by F.Cura et. al [19] views that crack propagation path and crack initiation point were strongly influenced by centrifugal load. Spur gears with different web and thin-rimmed were modeled before boundary conditions consist in displacement loads to simulate the presence of the whole gear.

\section{Analytical calculations method}

Analytical Calculations were one of the most important stages in designing a gear. Through this method, design and analysis of the spur gears to resist bending failure of tooth surfaces can be implemented.

\subsection{The Lewis bending equation}

Wilfred Lewis[20] in 1892 introduced the bending equation that remains the most common or basic standard for gear design. Lewis calculated stress in the gear using a cantilever beam under an applied bending moment[21]. A rectangular cantilever beam of crosssectional dimensions $F$ and $t$, having a length $l$ and a load $W^{t}$, uniformly distributed across the face width $F$. The section modulus $I / \mathrm{C}$ is $F t^{2} / 6$ end therefore, the bending stress is

$$
\sigma=\frac{M}{I / c}=\frac{6 W^{t} l}{F t^{2}}
$$

This basic formula being completed by including factor $y$ that is called the Lewis form factor, so we have

$$
\sigma=\frac{W^{t} P}{F Y}
$$

where $P$ is the diametrical pitch. The used of this equation for $Y$ means that only the bending of the tooth is considered and that the compression due to the radial component of the force is neglected.

\subsection{AGMA stress equations}

Based on Equation (2), ANSI/AGMA 2001-D04 and 2101-D04 contains dynamic factor $K_{v}$. Two fundamental stress equations are used in the AGMA methodology, one for bending stress and another for pitting resistance (contact stress). The fundamental equations are

$$
\sigma=W^{t} K_{o} K_{v} K_{s} \frac{1}{b m_{t}} \frac{K_{H} K_{B}}{Y_{J}} \quad \text { ( SI Unit) }
$$

where

$W^{t}$ is the tangential load, $(\mathrm{N})$

$K_{o}$ is the overload factor

$K_{v}$ is the dynamic factor

$K_{s}$ is the size factor

$m_{t}$ is the transverse module
$K_{H}$ is the load-distribution factor

$K_{B}$ is the rim-thickness factor

$b \quad$ is the face width of the narrower member, $(\mathrm{mm})$

$Y_{J}$ is the geometry factor for bending strength 


\subsection{Aida \& Terauchi - On the bending stress of a spur gear}

In 1962, Aida \& Terauchi [22] arrived at the conclusion that was rational to take the sharing force into attention for the calculation of the bending stress of a gear tooth. They have calculated the bending stress of a standard gear tooth by defining the thickness and the position of the weakest section and the worst loaded point.

Therefore, the subsequent formula has been presented for the bending stress of a gear tooth:

$$
\sigma_{t}=\left(1+0.08 \frac{S}{\rho}\right)\left(0.66 \sigma N_{b}+0.40 \sqrt{\sigma N_{b}^{2}+36 \tau N^{2}}+1.15 \sigma N_{c}\right)
$$

where

$\begin{array}{ll}S & \text { is tooth thickness on the weakest section } \\ \rho & \text { is the radius of curvature } \\ \sigma N_{b} & \text { is nominal stress } \\ \sigma N_{c} & \text { is compressive stress } \\ \tau N & \text { is nominal shearing stress }\end{array}$

the nominal stress $\sigma N_{B}, \sigma N_{c}$ and $\tau N$ can be calculated using of the following equations;

$$
\begin{aligned}
& \sigma N_{b}=\frac{6 P \sin \theta\left(l_{a}+l_{d}\right)}{S^{2} b} \\
& \sigma N_{c}=-\frac{P \cos \theta}{S b}-\frac{6 P \cos \theta y}{S^{2} b} \\
& \tau N=\frac{P \sin \theta}{S b}
\end{aligned}
$$

where $P$ is load, $\theta$ is the angle between neutral line of the tooth, $l_{a}$ is distance from the pitch point to the foot of the normal to the neutral line of tooth crossing the loading point, $l_{d}$ is distance between the pitch point and the weakest section, $b$ is tooth width and $y$ is the distance between the loading point and the neutral line of tooth.

Many researchers since then have performed analytical studies to investigate gear tooth bending stress [23-26]. Chen et. al [27] came out with a method for the calculation of root and contact stresses for metal, spur and helical gears. They verified their finding by finite elements calculations. Finding shows the spur gears, the location of the point of contact that leads to the critical tooth-root stress depends on the contact ratio of the pair of gears that rises with the number of teeth.

Li Shunting, since 2002 [11, 28-30] has come out with several studies on bending strength of thin-rimmed spur gears. One of his recent studies on analyses of thin-rimmed spur gear with inclined webs founds that the web location and the web angle of the thinrimmed gears have a substantial effect on the root bending stresses, the tooth contact stresses, and the joint stresses. His findings were aligned with the calculation from Miyachika [31], F Cura [19] and Opalic [32] that also take consideration on the effect of rim thickness and web arrangements on tooth bending strength of thin-rimmed spur gears. 


\section{Experimental techniques}

Reviews also revealed several set up to study gear strength been made by researchers. Most of the researchers focusing the leading causes of failure appeared to be tooth-bending fatigue, tooth-bending impact and abrasive tooth wear. From literature, there are two different approaches being conducted that are single tooth static test and gear pair dynamic test.

David B. Stringer et al [33] set up a new high-speed test capability for determining the high-cycle bending-fatigue characteristics of gear teeth. These test various in load circumstances and cycle-rates. The cycle-rate varied from 50 to $1000 \mathrm{~Hz}$. Li, Shuting [34] assembled a "power-circulating form" test rig to performed vibration tests of the thinwalled gear. The test was done at the speed range 500-3000 rpm and used strain gauge phase method to detect the resonance mode shapes of the thin-walled gears when they are running in a complete resonance state. M. J Handschuh et al. [35] established a test setup with equipment for the measurement of root stresses as shown in Fig. 4(b). They used an open-architecture gearbox with drive and load capacity equipped with motor and brake to operate gears under high-load and low-speed conditions. Later, a study by Qi Zhang [36] used a setup of The FZG test rig that was a back to back gear test rig of the closed power loop type.

A most recent study done by Pawar, P. B et al [37] prepared hardness test of composite samples and conducted an experiment using on Automatic Optical Brinell Hardness Tester with range $250 \mathrm{~kg}$ to $3000 \mathrm{~kg}$. A year before, Nizar Ahamed et al [38] develop a methodology which was tough for fault recognition of gears under fluctuating load and speed settings. A multiple-pulse independently rescaled-time synchronous averaging (MIRTSA) technique in conjunction with conventional time synchronous averaging has been projected. It has been examined that the proposed method improves the fault detection under fluctuating speed conditions. A similar setup was used by Nick Bretl et al [39] to investigate tooth bending strength of case hardened gears in the range of high cycle fatigue. A pulsator test rig is shown in Fig. 4(a) was consistently carried out the bending test.

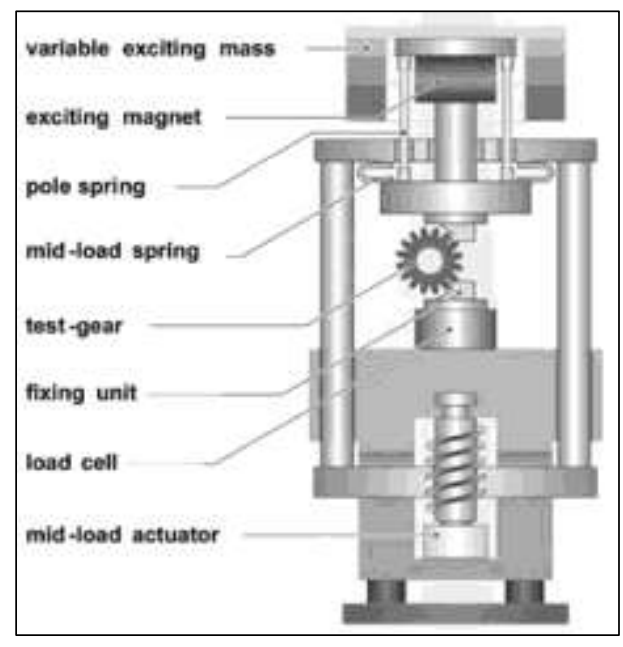

(a)

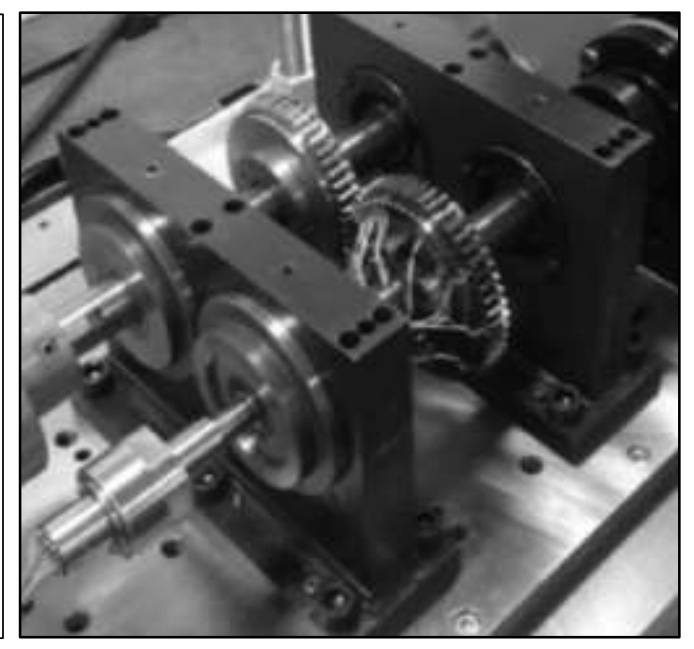

(b)

Fig. 4. (a) Illustration of a Pulsator Test Rig [39], (b) The gearbox setup for the measurement of root stress [35]. 


\section{Conclusions}

Failure of gear might occur in various type of modes from wear, bending fatigue, and tooth fracture. It is imperative for engineers and designers to perform an investigation on gear failure and most crucial is gear bending strength. From the reviewed articles, it could be concluded that there are several stages had been done in order to investigate gear bending strength.

1. Most researchers used the basic Lewis Bending Equation and AGMA Standards with modifications to get the first view of gear tooth strength. In fact, there are also some other equations such as Aida \& Terauchi Equation, and many researchers also try to formulate their calculations to predict gear strength.

2. The second stage is to simulate gears using Finite Element Method (FEM) in order to have the analysis of gear strength. Technological advances in FEM provides an opportunity for researchers to conduct various tests based on various parameters.

3. The most important stage is to put the gears to physical experiment or testing facilities to determine and validate all data from numerical calculation and FEM method.

This work has been done under the grant no. RDU 1403132 and enormous support from Universiti Malaysia Pahang. The authors gratefully acknowledge the support given throughout this project.

\section{References}

1 E. E. Shipley, "Gear Failure," in Machine Design, ed Cleveland, Ohio: The Penton Publishing co., 1967.

2 J. R. Davis, "GEAR MATERIALS, PROPERTIES, AND MANUFACTURE," in Mechanical Testing and Evaluation, D. Associates, Ed., ed USA: ASM International, Materials Park, 2005.

3 S. K. R. G.D.Bibel, M Savage, "Effect of Rim Thickness on Spur Gear Bending Stress," p. 15, 1991.

4 V. Savaria, F. Bridier, and P. Bocher, "Predicting the effects of material properties gradient and residual stresses on the bending fatigue strength of induction hardened aeronautical gears," International Journal of Fatigue, vol. 85, pp. 70-84, 2016.

5 A. Belsak and J. Flasker, "Detecting cracks in the tooth root of gears," Engineering Failure Analysis, vol. 14, pp. 1466-1475, 2007.

6 P. J. L. Fernandes, "Tooth bending fatigue failures in gears," Engineering Failure Analysis, vol. 3, pp. 219-225, 1996.

7 S. Pehan, J. Kramberger, J. Flašker, and B. Zafošnik, "Investigation of crack propagation scatter in a gear tooth's root," Engineering Fracture Mechanics, vol. 75, pp. 1266-1283, 2008.

8 C. Hu, W. A. Smith, R. B. Randall, and Z. Peng, "Development of a gear vibration indicator and its application in gear wear monitoring," Mechanical Systems and Signal Processing, 2016.

9 H. J. Decker, J. M. Certo, R. F. Handschuh, and T. L. Krantz, "Development of a new single gear tooth bending fatigue test capability," in 62nd American Helicopter Society International Annual Forum Phoenix, AZ, 2006, pp. 704-707.

10 K. M. Satoshi ODA, Takao KOIDE Toshiaki Fuji, "Dymanic Behavior of Thinrimmed Spur Gear with Various Web Arrangemants," Buletin of JSME, vol. 29, pp. 247-235, 1986.

$11 \mathrm{~S}$. Li, "Effect of addendum on contact strength, bending strength and basic performance parameters of a pair of spur gears," Mechanism and Machine Theory, vol. 43, pp. 1557-1584, 2008. 
12 G. Marunić, "Effects of rim and web thickness on gear tooth root, rim and web stresses," in Key Engineering Materials vol. 385-387, ed, 2008, pp. 117-120.

13 S. Glodež, S. Pehan, and J. Flašker, "Experimental results of the fatigue crack growth in a gear tooth root," International Journal of Fatigue, vol. 20, pp. 669-675, 1998.

14 J. Kramberger, M. Šraml, I. Potrč, and J. Flašker, "Numerical calculation of bending fatigue life of thin-rim spur gears," Engineering Fracture Mechanics, vol. 71, pp. 647656, 2004.

15 Q. J. Yang, "Fatigue test and reliability design of gears," International Journal of Fatigue, vol. 18, pp. 171-177, 1996.

16 T. Jabbour and G. Asmar, "Tooth stress calculation of metal spur and helical gears," Mechanism and Machine Theory, vol. 92, pp. 375-390, 10// 2015.

17 J. Zhan, M. Fard, and R. Jazar, "A quasi-static FEM for estimating gear load capacity," Measurement, vol. 75, pp. 40-49, 11// 2015.

18 N. Pedersen, "Reducing bending stress in external spur gears by redesign of the standard cutting tool," Structural and Multidisciplinary Optimization, vol. 38, pp. 215227, 2009.

19 F. Curà, A. Mura, and C. Rosso, "Effect of centrifugal load on crack path in thinrimmed and webbed gears," Frattura ed Integrita Strutturale, vol. 9, pp. 447-455, 2015.

20 W. Lewis, "Investigation of the strength of gear teeth," Proc. of the Engineers Club, pp. 16-23, 1893.

21 E. J. Wellauer and A. Seireg, "Bending Strength of Gear Teeth by Cantilever-Plate Theory," Journal of Engineering for Industry, vol. 82, pp. 213-220, 1960.

22 Y. T. Toshio Aida, "On the Bending Stress of a Spur Gear," The Japan Society of Mechanical Engineers, vol. 5, pp. 161-183, 1962.

23 D. G. Lewicki and R. Ballarini, "Effect of Rim Thickness on Gear Crack Propagation Path," Journal of Mechanical Design, vol. 119, pp. 88-95, 1997.

24 M. A. Sahir Arikan and B. Kaftanoglu, "Dynamic Load and Root Stress Analysis of Spur Gears," CIRP Annals - Manufacturing Technology, vol. 38, pp. 171-174, 1989.

25 Y. Pandya and A. Parey, "Experimental investigation of spur gear tooth mesh stiffness in the presence of crack using photoelasticity technique," Engineering Failure Analysis, vol. 34, pp. 488-500, 2013.

26 M. Ristivojević, T. Lazović, and A. Vencl, "Studying the load carrying capacity of spur gear tooth flanks," Mechanism and Machine Theory, vol. 59, pp. 125-137, 2013.

27 M.-H. Chen and W.-J. Wu, "Bending stress in gear teeth for variable surface pressure distribution," Journal of Mathematical Analysis and Applications, vol. 167, pp. 182202, 1992.

$28 \mathrm{~S}$. Li, "Gear contact model and loaded tooth contact analysis of a three-dimensional, thin-rimmed gear," Journal of Mechanical Design, Transactions of the ASME, vol. 124, pp. 511-517, 2002.

$29 \mathrm{~S}$. Li, "Contact Stress and Root Stress Analyses of Thin-Rimmed Spur Gears With Inclined Webs," Journal of Mechanical Design, vol. 134, pp. 051001-051001, 2012.

30 S. Li, "Effects of centrifugal load on tooth contact stresses and bending stresses of thinrimmed spur gears with inclined webs," Mechanism and Machine Theory, vol. 59, pp. 34-47, 2013.

31 K. Miyachika, B. D. I. Daing Mohamad Nafiz, and T. Asano, "Root stresses and bending fatigue strength of thin-rimmed helical gears (helix angle $\beta 0=10,20$ and $30^{\circ}$ )," in International Gear Conference 2014: 26th-28th August 2014, Lyon, P. Velex, Ed., ed Oxford: Chandos Publishing, 2014, pp. 836-845. 
32 M. Opalić, K. Vučković, and D. Žeželj, "Effect of rotational speed on thin-rim gear bending fatigue crack initiation life," in Key Engineering Materials vol. 488-489, ed, 2012, pp. 456-459.

33 B. D. D. David B. Stringer, Kelsen E. LaBerge, Andrew J.Zakrajsek, Robert F.Handschuh, "A New High-Speed, High-Cycle, Gear-Tooth Bending Fatigue Test Capability," 67th Annual Forum and Technology Display (Forum 67), 2011.

34 S. Li, "Experimental investigation and FEM analysis of resonance frequency behavior of three-dimensional, thin-walled spur gears with a power-circulating test rig," Mechanism and Machine Theory, vol. 43, pp. 934-963, 2008.

35 M. J. Handschuh, A. Kahraman, and M. R. Milliren, "Impact of Tooth Spacing Errors on the Root Stresses of Spur Gear Pairs," Journal of Mechanical Design, vol. 136, p. $10,2014$.

36 Q. Zhang, J. Zhang, C. Wu, Z. Xu, and S. Lyu, "The evaluation of contact fatigue strength for 20MnCr5 carburized gear," International Journal of Precision Engineering and Manufacturing, vol. 15, pp. 117-121, 2014.

37 P. B. Pawar and A. A. Utpat, "Analysis of Composite Material Spur Gear Under Static Loading Condition," Materials Today: Proceedings, vol. 2, pp. 2968-2974, 2015.

38 N. Ahamed, Y. Pandya, and A. Parey, "Spur gear tooth root crack detection using time synchronous averaging under fluctuating speed," Measurement, vol. 52, pp. 1-11, 2014.

39 S. S. Nick Bretl, Thomas Tobie, Karsten Stahl,Bernd-Robert Höhn, "Investigations on Tooth Root Bending Strength of Case Hardened Gears in the Range of High Cycle Fatigue," Thermal Processing for Gear Solution, 2012. 